\title{
Making contact: Experiences from the weight loss surgical clinic
}

Nicole M. Glenn, Faculty of Physical Education and Recreation, University of Alberta, Edmonton, $A B$, Canada

Email: nglenn@ualberta.ca

\begin{abstract}
Weight loss surgery is an increasingly common treatment for medically defined class III obesity and related comorbidities. A rise in demand has resulted in progressively longer waiting times in Canada, lasting upwards of ten years. Extended surgical waits impact the lives of people pursuing the procedure, no doubt - I wonder in what way? What is the experience of waiting to have weight loss surgery? I sought to explore this question using a human science approach to phenomenology of practice. It is within this broader inquiry that this particular text is situated. The multiple interviews I conducted with people who were awaiting surgery revealed the experiential import of contact, of touch, metaphorical and otherwise, to the overall waiting phenomenon. In this paper I consider this particular dimension of the wait - I question the experiences and meanings of contact that occur within the pre-weight loss surgical period. I reflect on the possible ethical and clinical significance of contact within this particular context while focusing on the relational aspect of the phenomenon, particularly between patient and clinician. Ultimately this deeper understanding of the experience as it is lived may elicit new and possibly more tactful ways of being with, of making contact - as in touch, hearing from or connecting with - within weight loss surgery-related clinical encounters.
\end{abstract}

\section{Introduction: Encountering Contact in the Weight Loss Surgery Clinic}

Weight loss, or bariatric surgery is an umbrella term used to describe a number of restrictive and/or malabsorptive surgical procedures intended to induce significant weight loss (Neff, Olbers \& le Roux, 2013). Some procedures involve cutting away or closing off a portion of the stomach, reducing it in size so as to restrict caloric consumption and retard stomach emptying. Others reroute or cut away a portion of the intestine, limiting the absorption of calories, vitamins and minerals. While some procedures do both - reducing consumption and absorption (Neff et al, 2013). Bariatric surgery is the most effective treatment available for class III obesity (i.e., extreme obesity, clinically significant obesity; Body Mass Index (BMI) $\geq 40 \mathrm{~kg} / \mathrm{m}^{2}$; Neff et al, 2013). It is estimated that 1.5 million Canadians could qualify for bariatric procedures yet only about $0.1 \%$ receive the surgery (i.e., publically funded procedures; Padwal, Chang, Klarenbach, Sharma, Majumdar, 2012a). People are literarily dying while waiting to have the procedure (Christou, \& Efthimiou, 2009). Waiting, within this context, is no doubt significant for the individuals in the queue, however, the impact this wait has yet to be thoroughly explored 
(Padwal, Majumdar, Klarenbach, Birch, Karmali, McCargar et al, 2012b). Preliminary investigation suggests it has a profound impact on quality of life and physical as well as psychosocial wellbeing (Padwal et al, 2012b). I wonder what is it like to wait within this context? How is the potentially lengthy period prior to bariatric surgery lived by those who wait?

The bariatric clinic is a place where patients and clinicians interact, connect, and make contact with each other. The wait for bariatric surgery, in Canada, averages 5 years but can stretch upwards to 10 years depending where a person lives (i.e., the time from referral to surgery; Christou \& Efthimiou, 2009). People can wait years before they are even on the formal waiting list, before even entering the queue; waiting to wait so to speak. Once clinical visits begin, the wait can stretch on for a time, years perhaps. Within these waits there may be many opportunities for contact, a touch or a word, between clinic and patient; there may be many opportunities missed as well. I wonder what is the significance of contact within this context? What does the experience of contact mean to the people who are waiting to have weight loss surgery?

I contemplate the word - contact - it is a state or condition of touching, meeting or communicating; it is a person carrying a contagion or a connection for the passage of an electrical current (Barber, 2004, p. 327). Contact originates from com-tangere meaning withtouch (Barber, 2004, p. 327). I wonder, however, what does it mean in a clinical context? What about in the context of the pre-bariatric surgical waiting period? It surely is not an experience of connecting electrical currents or the carrying of a contagion, is it? It must be a touch - instrument to skin perhaps, or getting in touch with - clinic to patient or patient to clinic, and also meeting appointments arranged and attended. These are the modes of contact one may expect to experience within the wait to have reducing surgery. Lingis $(2005,2007)$ and Levinas (2006) articulate contact in another way, as con, that is with, tact. This con-tact is an ethical way of being in relation, a kind of seeing that acknowledges the other as unique, as truly and inescapably other. This con-tact calls forth responsiveness, a being for the other. One would hope that this form of contact is experienced within the bariatric clinic between patient and clinician; however, this may not always be the case.

A person who decides to pursue weight loss surgery may be subjected to numerous tests, screening processes and procedures prior to surgical approval. During this pre-surgical waiting period one may find oneself observed, measured by clinicians, technicians and tools that are intended to see scientifically, objectively, to see through the exterior and into the materiality of the body and somehow determine what the outcomes of this surgery might be. In the attempt to see in this way, however, what might be missed? Levinas (2006) offers some insight here. He writes about the relation between one and an Other as a possibility for tactful engagement, an ethical way of being that extends to being for the other. This engagement requires a seeing and openness to the other in their otherness,

To meet another, one must first welcome a face. This means more than looking at the features in the other face, or the color that characterizes the surface of his skin, or the iris of his eyes - as if in doing so one could perceive, grasp, know. Is not the face first of all expression and appeal, preceding the datum of knowledge? (Levinas, 2006, p. 191)

This kind of ethical seeing that is an appeal, an authentic call, from one to an Other, 'precedes the datum of knowledge,' as Levinas writes. It requires seeing beyond the universal, beyond the results of tests and clinical measurements. How might this kind of seeing, this form of contact 
take place within a clinical encounter? Is it even necessary or desired? I wonder what other forms of contact may take place within the period of waiting to have weight loss surgery? What might be the significance of these experiences to the one who waits?

\section{Methodology}

This phenomenological inquiry followed the human science research and writing practices of Max van Manen (1990). I entered the clinic environment as a researcher, a phenomenologist interested in the experience of waiting to have bariatric surgery - the larger research project in which this particular inquiry is embedded. I am not a clinician, nor did I have a previous relationship with this particular bariatric program. This research inquiry was conducted independently of the clinic; however with their approval. All research-related activities (e.g., interviews, analysis), excluding recruitment and observations, took place outside of the clinic environment. The study was approved by the university ethics review board as well as the ethical review boards for the local health region and the specific hospital from which recruitment took place. All participants were greater than 18 years of age and signed informed consent.

I recruited participants from compulsory, pre-surgical education sessions conducted at a publically funded bariatric clinic in Western Canada. Seven individuals agreed to participate and were selected based on their interest in participation and their ability to communicate proficiently in English. Recruitment ceased upon the collection of sufficiently rich, descriptive lifeworld data. Participants had been approved for bariatric surgery (by the bariatric surgeon at the clinic) and were waiting for their surgical date when the first interview was conducted. These phenomenological interviews were open-ended and oriented to the phenomenon as it arose in each participant's unique experience, rather than being structured or semi-structured as are more commonly used techniques among qualitative data collection. My aim was to gather prereflective, concrete, experiential descriptions (i.e., not judgments, opinions, theories and so on) of the phenomenon and, as the interviews progressed, to begin reflective questioning. Following the initial interviews, preliminary analysis and writing, I engaged in follow up conversations with all interested participants (four of the seven agreed to follow up conversations). These conversations contributed additional lifeworld material as well as served as a hermeneutic exercise where, together, we reflected on emergent insights and phenomenological themes that arose through preliminary writing, reflections, and reductions. All interviews were recorded and transcribed verbatim. They were analyzed using phenomenological reduction and reflection practices, described more accurately an approach or attitude rather than specific step-by-step techniques (van Manen, 1990).

With this text I aim to present glimpses into possible meanings of the phenomenon. I focus on six phenomenological themes that emerged in response to the question - what is it like to experience contact while waiting to have bariatric surgery? Contact within the bariatric clinic may be waiting to hear from - waiting to wait so to speak; it may be momentary, a fleeting experience, a tease; it may be passing off or passing over; contact may be a gnostic touch - the palpating hands of a physician; it may be a pathic touch, a caring gesture of felt understanding; and contact may be an invitation for one to be honest, to show oneself to an Other. These glimpses into the experience as it is lived by the people who have waited to have weight loss surgery may bring to the fore the hidden, taken-for-granted or assumed and thus deepen our understanding of the phenomenon as it is within the everyday lifeworld. This understanding may 
inspire a pause in practice, a moment to consider and in doing so perhaps shift our way of knowing, and even our way of being, so as to allow space for new, more tactful and ethical practices to emerge. This may be particularly relevant to the caring or clinical professions that populate the bariatric clinic. Baron (1985), a physician and phenomenologist, argues that phenomenological understandings might help bridge the schism between physicians and patients. He reflects on his own experiences and writes, "It is as if physicians and patients have come to inhabit different universes, and medicine, rather than being a bridge between us, has become one of the major forces keeping us apart" (p. 606). He contends that phenomenology within medicine might help the field and those practicing within it to "(...) rediscover and realize the human goals of medicine" (Baron, 1985, p. 606). It is to the human, the experiential dimension of being a patient waiting for weight loss surgery that I now turn.

\section{Not Even On Hold: Waiting to Hear from the Weight Loss Surgery Clinic}

Jane, a woman who is waiting to hear from the bariatric clinic for the first time, describes the significance of the wait, of the procedure and the life that she hopes to attain,

I feel like a small child a Christmas. The excitement I feel about having this surgery is how I once felt before waking up and running down the stairs to find that Santa had come. 'I want this surgery,' I think to myself. I will do whatever I have to do, jump through any hoops, say anything I need to, anything the clinic staff wants to hear to get the surgery. I don't think most people understand what it is like to want this. 'I feel hopeful for the first time in a long time. I feel hopeful for something I've long given up on.' (Jane)

Jane wants weight loss surgery-- she's desperate to have it. She will do whatever needs to be done to access it; she'll jump through hoops and do what the clinicians ask, anything to get surgical approval. The promise of the surgery may be the promise of hope for Jane. With the promise of surgery Jane may find the promise of new beginnings and transformation and the promise that things she had given up on may actually be possible. Waiting to hear from the clinic Jane feels like a child on the precipice of Christmas morn, bubbling over with excitement and anticipation. She cannot wait for the surprises she hopes are in store - what is in store, she may wonder. In store may be a bright future free from discomfort or from pain, free from health related worries that take the shape of "not if, but when." In store for Jane may be a slimmer body, a lower number on the scale. In store may be the ability to shop at "normal people clothing stores," as another woman waiting to have the surgery explained. In store may be a better fit seats that welcome rather than pinch and bruise, stares that appreciate and admire rather than judge and ridicule. During the pre-weight loss surgical period possibilities abound, at least so far as one awaiting the surgery, like Jane, may anticipate. Yet, weight loss surgery is not like Christmas. The twenty-fifth of December will come each and every calendar year without fail. It may not be celebrated in the same way, with equal measures of gift giving and celebratory mood, but one can be sure that the date will arrive and it will be Christmas day. Bariatric surgery, however, may not arrive with such certainty. It may not arrive at all. A person does not simply apply, wait her turn and then undergo the procedure as Carol explains, 
I submitted all my forms ages ago. I've actually had a baby during this time. A baby! That's a long time to be waiting for something. It has felt like forever. At this point I've pretty much given up on waiting to hear from the clinic. They've not been in touch with me once since my referral was sent. No contact- not even, "oh you're on the list, on hold." Nothing. Nothing at all! (Carol)

Carol articulates the uncertainty of the connection between herself and the clinic while she waits to hear from them for the first time. She does not even know if she is on hold. This is different than the experience of awaiting other surgical procedures, such as atheroplastic joint surgery or a liver transplant where patients describe waiting as 'life on hold' (Brown, Sorrell, McClaren \& Creswell, 2006; Parsons, Godfrey \& Jester, 2009; Sjöling, Ågren, Olofsson, Hellzén, \& Asplund, 2005). Is the wait to hear from the bariatric clinic for the first time a life waiting to be on hold? Or perhaps this is the pre-holding area, the 'wait to hear from' void. Knowing there is much more waiting to come a person may just want to start waiting, to get to it, so to speak. Instead one may be waiting to wait - a no man's land of pre-waiting that can stretch out infinitely ahead.

Carol has reached out to the clinic, submitted her forms and expected that she has entered the queue. Should they not reach back to her? At least let her know her application has been received, is being reviewed, and is complete? Should she not expect some kind of contact in return? So much time has now passed that Carol is no longer the same person she was when she first applied. She is a mother now. What else will transpire in her life while she waits to hear from the weight loss surgery clinic? As her life continues to move forward marked by transitions, big and small, she wonders if her forms have been lost or if she has been forgotten, perhaps they were not submitted after all? Maybe her doctor forgot to send her referral forms on or there was information missing and they've been tossed out? The wait for first contact stretches indefinitely before her and Carols appears to find herself in a black hole of sorts, a contactless void where time and space cease to exist, at least when it comes to this wait to hear. The rest of her life, as she explains, keeps chugging along but the wait, well she doesn't even know if it is a reality. "Am I waiting?" she asks herself over again.

On the other hand, the wait-to-hear-from that feels like a black hole may also represent limitless possibilities - a space where anything could happen. Nevertheless, whether anything or nothing, infinite or limited, nothing is certain. Without any word from the clinic the person who waits, like Carol, must imagine the reasons, fill in the blanks with her own stories and continue to try to make sense of the void that is this uncertain time of not-quite-waiting. According to Levinas (1978) this is precisely where hope may arise. He writes, "All the acuteness of hope in the midst of despair comes from the exigency that the very instant of despair be redeemed...hope hopes for the present itself...at the very moment where all is lost, everything is possible (Levinas, 1978, pp. 94-95).

Contactlessness, as in the non-response to the reaching out of another, such as described by Carol, may be experienced as gesture of carelessness, a non-touch, a void. Why would the clinic not call or write to say they had received her forms? Carol may feel this means she is unworthy of their time, their energy and their care. Nothing, not a word from the clinic during this time, may be experienced as nothing, a void; a black hole perhaps, limitless and empty. However, there may be more to it than that. Carol may feel like she is nothing as she reaches out for connection and hears nothing in return. The wait to hear from the clinic may be a wait to hear 
back, a wait for response, a wait for responsiveness, for connection and care. One may be reaching out for more than a place in the queue, one may reach out as a question, 'am I worth it?' One may be secretly fearful of what the response might be, yet hopeful all the same. The lack of acknowledgment from the clinic during the first stage of waiting may be received by the one who waits as a message that confirms the feelings one may have of oneself, "not a bit, you are nothing and so you get nothing'

A person may seek out weight loss surgery for a multitude of reasons. Perhaps one hopes for better health, freedom from infirm and pain. Perhaps it is a more active and fulfilling personal life that one seeks, renewed desire and increased attention. One may hope that surgery will bring about a kind of normalcy previously only imagined, the ability to walk down the street without ridicule and shame. Perhaps it is another reason entirely that moves a person to wait. Regardless of motivation, however, one may anticipate that this surgery will bring transformation, transformation of body and perhaps of self (Throsby, 2008). One may hope that weight loss surgery will bring about a different way of being in the world and maybe the world will be different in return (Throsby, 2008). Is it possible that it could be a little less harsh, less judgmental?

In this way the move toward surgery, the request for referral and subsequent wait for contact from the clinic may be more than a 'wait to hear from.' It may be wait for an open door to beckon one forward, into the future and a new way of being in the world. Yet, I wonder how much contactless silence can be endured before a person gives up all hope of ever being invited into the future full of possibilities? How long until Jane's excitement and anticipation fades and then disappears? What may have been a hopeful space, a time of beginnings and promise instead appears to transform into a contactless void full of uncertainty and the unknown. A woman waiting to have the surgery tells me, "I want to call and say have you forgotten about me, was my application lost, what's going on?" Yet she does not, but rather, continues to wait to hear from the clinic and grasp at hope at it slowly slips into the silence.

\section{Hearing From as a Tease}

It was like any other day. I just grabbed the mail and headed into my house. Then I noticed the letter from the clinic. I felt my heart skip a beat. Could this be? I had almost forgotten about the clinic, almost, but not quite. I immediately phoned my husband and then my sister. 'I've heard from the weight loss surgery clinic!' I almost shouted into the phone. Then I felt a knot in my stomach. Panic was setting in; I need to make travel arrangements, what should I expect, where is all the information I need? (Sara)

What began as an ordinary day may be made extraordinary through the receipt of a letter. Amidst the bills, advertisements and occasional card received in the post this letter seems to stand out. On first glance it may look like the others, a white or beige envelope, typed address on the front. But, then, there is the return address imprinted in the top left corner, the clinic name clearly announcing the wait to hear from is over. Excitement and anticipation collide, as the envelope is ripped open. "What do they have to say to me?" Sara asks as she skims through the contents looking for clues. "Am I in? When do I start? What now, what next?" "The letter of acceptance," as one woman waiting for the surgery put it, contains information about the program and details of the educational courses, or 'modules' that must be completed before a first appointment will 
be booked. In the letter, a person may find contact information for the clinic and a date by which she must respond to indicate continued interest in the program. On the contrary one may find in this letter very little information about how to get a hold of the clinic and be left feeling like the intended message was, 'don't call us, we'll call you.'

The arrival of the letter from the weight loss surgery clinic may mark a moment long awaited. The black hole, the contactless void has slipped away and in its place, a letter, a ray of hope; a touch in response to the reaching out. This touch may be tentative, fleeting even, like a whisper that is felt and then disappears. Sara, the woman who shared her experience of receiving the letter went on to explain,

Weeks have passed since I've received the letter and since then there has been nothing, I've not heard from the clinic at all - no follow up, no phone call, no contact at all - like 'Here you go and keep waiting.' The letter just feels like a tease. I think, 'Come on lets go, lets get a move on, lets get this started!" (Sara)

Excitement and hope may begin to transform into uncertainty and dread as a person realizes that this is only the beginning, yet again. The wait to hear from the clinic, the nothingness of silence that preceded the request for entry into the surgical queue, seems to be replaced with a new kind of wait; a waiting that is the wait for surgery. Although the uncertainty of waiting, as 'am I waiting at all?' falls away the moment the letter is received, it may be supplanted with a new kind of uncertainty, that of 'what now, what next, and when?'

With the letter from the clinic the clock may begin to tick on this wait, it's been five days, five weeks, or five months since the letter arrived. Time may feel less like a vacuum, an infinity that slips in and out of one's consciousness, and more like a presence, something to be counted in minutes and days, something to be tracked and measured. Impatience may replace the cycle of hope and hopelessness that was, as one feels time slowing with this new form of uncertainty. Questions are left lingering as one searches the letter for answers. "Is this a form letter? What does this letter say about me? What does it say to me?" I wonder how might this moment be experienced differently if one had received a phone call instead? What about an email? What might the form of contact say about the value or worth of a person being contacted? An email or phone call are immediate, letters can take a week or even longer to arrive. Letters can be immensely personal, hand written in swirling script, or decidedly impersonal, lost amidst junk mail and bills. Receiving a letter from the clinic may feel like a careless gesture - Am I not worthy of the time it takes to make a phone call? A person may wonder, is my time so unimportant that I should wait another week to receive this notification by post? Am I so unimportant? Particular to the wait to hear from the bariatric clinic this mode of contact may feel especially thoughtless. Like Carol and Sara, people who are waiting may have been waiting to hear for a very long time already, waiting without even certainty that they were waiting at all. The extra time it takes for the letter to arrive may feel like another sign, among many, that the person who waits for this surgery is less than, unworthy and uncared for (Lupton, 2013).

First contact from the clinic may feel like a tease, a touch that holds promise of one thing but delivers another, or perhaps it delivers nothing at all. To be teased is to be made fun of and can come out of kindness or out of cruelty. To be teased is to be lured into thinking something will arise when it does not and was, in fact, never going to. What is it like to feel teased? Perhaps we enjoy the teasing of a friend, a parent or a lover. This kind of teasing may be a gesture of playful affection, demonstrating closeness and intimate knowledge. On the other hand, teasing 
may be an unwelcomed picking apart, a passive-aggressive saying without really saying leaving one feeling uncared for and hurt. An unfulfilled promise may feel like a tease, a pulling away of that which was expected and desired. This mode of teasing gives the impression of unequal power, where the one teasing holds all of the strings, and like a puppet master with a marionette, makes the other dance at will. Sara feels teased by the clinic in just such a way. For her, the letter was a sign that contact had begun - and perhaps it had-but not in the way she had expected. She anticipated hearing from the clinic; the moment of first contact would be the beginning of a relationship, a two-way exchange between her and the clinic. Instead, she learns to read between the lines of the letter received - don't call us, we'll call you - and feels distinctly out of touch and alone.

\section{Contact as a Refusal: Being Passed Off and Passed On}

Jasmine recounts the moment where she requested a referral to the bariatric clinic from her family physician. This moment has stayed with her years after the referral was made,

"Can you refer me to the weight loss surgery clinic?" I asked my family doctor. He hesitated and then said, "Okay," but he didn't seem to know anything about it nor care for that matter. It was like, "Whatever. Here you go, here is your referral, now away you go." I don't even think he looked up from the page he was signing to look at me. I have seen him since and he doesn't even ask about it. I have to contact him when something comes up. I'm trying to get my weight and my health under control and it's like I'm doing it on my own. I am sure he feels I just need to eat less and move more so he's happy to pass me off to a different doctor. (Jasmine)

In requesting a referral for the bariatric clinic Jasmine seems to be asking for more than a signature on a page. She is reaching out to her doctor with hope, perhaps, that he may reach back, acknowledge her and offer her support. She may be hoping for a connection that is recognition and maybe even a nod of approval, "yes, you are deserving of this surgery, yes, I will be in your corner," she may imagine him thinking. Instead he does not look up from the form that he signs. He does not look at her. She is left feeling as if he thinks her weight is her fault, her problem, not his - eat less and move more - she can feel it, although unspoken. She's heard this a million times before and from a million different people, or so it seems. She thought he would be different, he would know better, he would understand and that he would care.

The recognition of one by the other, expressed through a look, a touch, or a gesture may be similar to the mode of responsive contact described by van Manen (2012); the kind of contact that elicits a sense of responsibility an ethical way of seeing the Other. Instead, Jasmine is refused. She is passed off, so it feels, from his hands to another's, although he does not seem to care whose. What is it to pass off? Passing off happens to things we no longer need, want, or have any attachment to. We may pass off something that is a nuisance, something we no longer care for. Being passed off may be experienced as a deliberate but thoughtless touch - an empty space in which one is alone although in the presence of others. To be alone among others may be different than being alone as in solo, by one's self. Imagine there are people all around and not one of them understands you, or perhaps even cares to? This is a profound kind of aloneness, an aloneness that may be isolating, silencing, dismissive. 'You are not worthy,' it whispers. 
Like embarking on a solo expedition, a person who is waiting to have bariatric surgery may feel they are going it alone. However, quite unlike such an endeavour, where the solo expedition may be taken on by choice, the companionless journey towards bariatric surgery may be neither expected nor desired. One may reach out for support, for companionship, like Jasmine, and be refused. Jane, who earlier described the surgery as Christmas-like, explains, "I am shifted from person to person. I'm seeing a third nurse in two months! There is no constant companion for this journey." Instead of companionship she finds isolation; instead of guidance and support she may be passed off or passed on. This act may be intended as a motion toward the future, a passing from one stage to the next, yet as it is experienced, beyond the control of the one who is passed, it may feel like a hostile move, a careless and tactless gesture. This mode of contact is quite the opposite of con (with) - tact, as articulated by Levinas (Robbins, 2001) and Lingis (2007). The ethical way of being with (and for) the Other, responding to the call of their being. Levinas (2006) writes,

Between the one that I am and the other for whom I answer gapes a bottomless difference, which is also the non-indifference of responsibility, significance of signification, irreducible to any system whatsoever. Non-in-difference, which is the very proximity of one's fellow, by which is profiled a base of community between one and the other, unity of the human genre, owing to the fraternity of men. (p. 6)

This ethical way of being with the Other is a human way of being, not specific to the clinical encounter, per se. What are the possibilities for this mode of con-tact between clinician and patient? What is the meaning of con-tact to the person who is waiting to have bariatric surgery? The refusal that is the experience of non-con-tact may be isolating leaving a person to feel unseen and alone, refused and unworthy. The refusal is a sign of indifference, as Levinas describes, a non-seeing of the uniqueness of the Other and a reduction to the general case. Is this not the practice of contemporary medicine - the reduction to the same, the seeing beyond the unique to the shared, seeing under the skin to the very core, to the cells? How might a physician in the bariatric clinic see the general so as to diagnose and treat yet also see the unique so as to care and respond?

\section{The Gnostic Touch of Contact as Reducing to Sameness}

Moments of generalization and categorization cannot be avoided within the bariatric clinical encounter, or, within any clinical encounter it seems. Measurement and testing are a hallmark of contemporary medical practices and can lead to diagnosis and treatment, to cures of illness and pain. There may be different ways of being within the clinical encounter, however, as van Manen (1999) describes. The clinical touch or way of seeing can be gnostic, as in dia-gnostic, a technical way of being, probing for answers and palpating beneath the skin. The clinical touch can also be pathic, as in em-pathic and sym-pathic, an embodied, relational way of being, seeking to understand, to worry and to care. The gnostic touch is the more common way of being between clinician and patient. I wonder how the person who is waiting to have bariatric surgery experiences this gnostic touch? What possible meanings might of this form contact imbue?

Rachel is waiting to be approved for bariatric surgery. To qualify, she must undergo screening, including providing a detailed medical history. She describes the conversation she has with the intake physician, 
The doctor asks me about my sore knee and then goes onto say, "oh so you got a bit of arthritis." "No." I respond. I know that this already because my family doctor x-rayed my knee just last year. There is no arthritis. I am sure of that. I know that pain in my knee comes from a muscle problem, probably because of bad shoes. I walk so much and I haven't been careful about my shoes. I try to tell her all of this but she's already onto the next question. I think, “Okay, so I didn't get that story out. The doctor thinks its arthritis and there is nothing I can say to convince her otherwise." I know there are two things wrong in my chart now. "Oh well," I think, "I'll just let it go." (Rachel)

The physician's trained gnostic eye may see the pain in Rachel's knee and the weight of her body and know how the two are related - this pain was caused by the weight, this knee is arthritic, the physician appears to conclude. The gnostic seeing of the physician intended to capture Rachel's detailed medical history may capture her instead, entrapping her within an expected history, and reveal nothing of the truth of who she knows herself to be: a walking enthusiast, a buyer of cheap shoes perhaps. She is not the 'stereotypical fat person,' the lazy, the

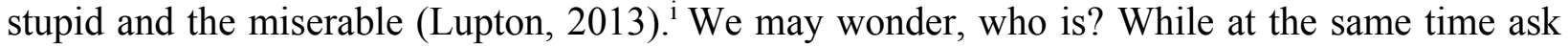
ourselves, can a fat person really be more than her material body, more than what can be seen with our eyes? Contemporary depictions and understandings of fatness show otherwise - the fat body is first and foremost fat (Lupton, 2013). Scott-Dixon (2008) writes,

Fat is many things, including a tissue; a signifier and symbol; a self concept; a set of experiences; and an identity that is constituted in relation to others, (sub)cultural norms, and systems of power and privilege. Fat is a curious and contradictory thing, both hypervisible and invisible; both associated with femininity and desexualized. It simultaneously signifies both poverty and abundance; public concern and private well being; inadequacy and excess. . . Fat is often used in the same way as obscenity: nobody can quite agree on a definition, but we feel we know them when we see them. (p. 24)

Rachel may be obese, fat, "big-boned, plus-size, thick, curvy, voluptuous, padded" (Taylor, 2013, para. 2), depending on who is doing the labeling, that is why she is here at the clinic for treatment, yet she is also infinitely more. She is herself and the stories she tells show that self to the world. What then if these stories go unheard? What does it matter if the physician sees her as she is, not as she is expected to be?

The gnostic touch of the physician is intended as an information-gathering touch, a quest for particular forms of knowledge, for understanding and classification. In the clinical encounters that take place prior to bariatric surgery it is frequently weight and height that are recorded, and blood sugar and insulin levels that are tracked. Weight histories, weight loss attempts and comorbidities (i.e., related medical conditions) are important and necessary to the clinicians providing care at the bariatric clinic. With such a focus, however, what might be lost or remain unseen? Robbins (2001) writes,

The achievement of knowledge consists of grasping the objects. Its strangeness is then conquered. Its newness, the opening up of its otherness, is reduced to the 'same,' to what has already been seen, already known. In the ethical relation, the other man remains other 
to me. Despite our exchanges, he remains that which I - closed up in myself - am not. (p. 191)

There may be little space for strangeness within the clinical encounter, particularly within the bariatric clinic where queues are long and care provision stressed (Christou \& Efthimiou, 2009). There may be little desire or felt need to face the unfamiliar within that which is increasingly familiar: 'the problem of obesity,' the fat body, ill and in need of fixing, the epidemic that is sweeping the globe (World Health Organization, 2011). We presume to know so much about the obese body, and the person by association (Lupton, 2013; World Health Organization, 2011). Are we really open to understanding differently? How might this presumed knowledge influence experiences of contact within the bariatric clinic?

The contact experienced through the gnostic touch may reduce and silence a person - it may not invite the other to be as she is but instead command her to be as she should be, the 'general case,' severely obese. The palpating, gnostic hands of the physician may be almost undistinguishable from the sterile metal tools they so deftly employ. These are hands that know; they know bones and muscles, tissues and cells; they know of life and death. But what do these hands know of the person - the one whose warm skin they prod? What do they know of her pain and suffering? What do they know of the story she tells of her self?

\section{The Pathic Touch of Contact: Making the Wait (Weight) Fall Away}

Sara is waiting to have bariatric surgery; she is in the hospital being prepped for her procedure. She may be excited and nervous; things are going to change. She may think, what will it be like after surgery? She has been to the information sessions and done her homework, reading online and talking to others, so she knows what to expect. She also knows to expect the unexpected; she knows that each case is unique and that she may respond differently than others. These thoughts may be occupying her mind as she sits alone in her hospital room.

I keep checking the clock to see if it's time for me to go yet, time for them to come and get me and wheel me to the operation theatre. The walls are white and I can hear the clock, tick, tick, tick. I'm excited and I'm nervous. I feel sick to my stomach all of a sudden. Am I doing the right thing? Do I really want this? The nurse is in the room adjusting my bed, checking my vital signs, my heart rate, blood pressure and other presurgery prep stuff. He starts chatting to me about some show he was watching last night. It turns out it's a show that I watch too! We're talking and laughing away and I forget to check the clock. It feels so normal. Like I'm not there waiting for this surgery. (Sara)

In the final moments of waiting for weight-loss surgery, Sara finds the ticking of the clock broken by the warm voice of the nurse who is there to take her vital signs. He has her lean forward and breath out as the cold stethoscope touches her back - a gnostic gesture to be certain! - Then he begins to chat. He talks about the unexpected plot twist in his favourite television show watched the night before. He asks if she watches too. (Contact is made!) They begin to laugh, losing themselves in the lives of the fictional characters. 
The gnostic palpating touch of the nurse, the cold stethoscope on warm skin, is felt, yet it is not that touch that grabs Sara's attention. It is the pathic touch, the relational being with the nurse that she recalls from that moment, the conversation, the being seen and treated as if she were just another person, not someone with class III obesity awaiting reducing surgery. The wait falls away as she is swept up in the conversation. She forgets, only momentarily, the ticking of the clock that signifies this wait is coming to an end, or at least the pre-surgical wait. A new wait stretches out ahead of her into the unknown. "Am I doing the right thing?" She questions as her nerves begin to set in. She cannot know the outcome of the surgery and the future that it will bring yet she sits contemplating these things all the same. As she enters into the world of her own head; the solitary, personal space of thought and of doubt, she slips away from the relational world. That is, until she finds herself pulled into conversation with the nurse who is charged with her care. She may have been able to continue thinking about the 'what ifs' and 'what nexts' if not so compelled by the chatter of the nurse. His touch, the coldness of the instruments he employs may have only intensified her thinking, acted as a reminder of what was about to transpire. Instead, however, she finds herself in conversation - conversation originates from the Latin com-vertare, literally to "turn about with" (conversation, Online Etymology Dictionary, n. d.) - turned about by the act of being with her nurse in this way.

There is something so ordinary about a conversation, even within the hospital walls, we may not think of it as a way of being with, in particular a clinical way of being with an Other. Yet the etymology of the word reveals its rootedness within the communal relation coming from conversatio or conversari, which means the act of living with and to live with, keep company (Online Etymology Dictionary, n. d.). Nevertheless, Sara's account reminds us of the possible significance of such moments and the meaning they may hold. It is an ordinary encounter, a 'meaningless' conversation that brings her out of herself and into the world. Through this conversation, she is connected to the nurse, not through his probing touch, but through his voice, the pathic touch of his words and gestures. His invitation to enter into ordinary conversational relation is recognition that she is human, not unlike any other (and at the same time completely unlike any other), not a fleshy mass in need of reduction. Such moments of contact, the pathic touch of a nurse or physician, may offer reprieve from the weight, the waiting and the body that others may find difficult to see beyond.

\section{Contact as an Invitation to be Honest and show Oneself}

There was this doctor at the clinic. She was wonderful. She asked a question and then waited patiently for me to respond. She just sat there quietly until I did, not taking notes, not doing something else, and just sitting there with me. She listened to what I had to say too, she would ask me more questions after I had told her what I was thinking. She said, "You should research the different types of surgery and make the choice depending on works best for you." I feel I can be honest with her, and really talk to her. (Carol)

Creating space for the other to be, the silence of listening can be an invitation, a calling forth of one to the Other, 'I am here. I see you as you are,' it suggests. To ask a question and wait, quietly for a response, listening without impatience, without intention or pre-conception is the listening of con-tact (i.e., with-tact), of ethical responsivity (Lingis, 2005, 2007; Levinas, 2006). Engaging with Carol in this way, listening and asking, the physician shows respect for her as a person, 
respect for her knowledge and also for whom she is and knows herself to be. The physician is not judging, scribbling notes on the page to later review. She simply listens. This may invite Carol to open up, to be honest in ways she has previously felt unable to do.

People waiting to have bariatric surgery report enacting the 'ideal patient' role, feeling they need to do and say what is expected rather than what is truthful (Drew, 2008, 2011). As such, they may feel they must hide themselves, "I will do whatever I have to do, jump through any hoops, say anything I need to, anything the clinic staff wants to hear to get the surgery" explained Jane as she describes the meaning of weight loss surgery to her. You can almost hear the desperation in her voice. This surgery is something she wants; something she needs. She feels it is her last hope. At the same time, patients may feel the clinicians at the bariatric clinic cannot be trusted; that they are looking for excuses to deny access to the much-desired procedure (Drew, 2008, 2011). As such, the person waiting may find it difficult to open up, to show herself as she is, to reveal her fears and her failings within this particular clinical context. What is more, people who pursue this procedure may already feel their failings are on display, to be read on and through their bodies (Lupton, 2013). They may not wish to perpetuate the image of their failed selves and perhaps worry that (perceived) shortcomings will prevent them from receiving the surgery. In comparison, for example, a person waiting for hip replacement may reveal the full extent of their pain and worries to their care provider, unafraid that these concerns will hinder their opportunity for treatment. The person waiting to have a hip replaced has no need to 'prove' worthy of the surgery. This is not the case for a person pursuing bariatric surgery. Diet journals tracking each and every morsel consumed are completed and assessed. Weight loss success during the waiting period prior to surgery proves that one is 'on the right track' and a 'good candidate' for the procedure. One must show capacity for the right behaviours, show that one can and should be trusted with a new stomach, with a new way of eating and a new life. How might one feel trust in return? Respectful contact, the listening silence that does not judge but hears with openness, may elicit honest, truthful communication between patient and clinician; it may lead to new ways of being in relation in this clinical context. A physician at the bariatric clinic once said to me, "I wish I could I know what my patients were thinking, what they were truly feeling and hoping to get from this surgery." Maybe he could, maybe he needs to ask and listen in particular ways - make con-tact.

\section{Concluding Reflections}

Contact, experienced in relation to the wait to have bariatric surgery, may be a gesture of worth. The contactless void of the wait to hear from the clinic for the first time and the letter received through the post may suggest to the one who is waiting, "You are not worthy of more, you are not worthy of this care." This may be particularly salient to the individuals who pursue this procedure because these feeling of worthlessness and disregard may not be new, and perhaps not unexpected (Lupton, 2013). They may even confirm thoughts a person has of herself. Many individuals I spoke to mentioned convincing themselves that they deserved to have this surgery and that they were "doing something for myself for the first time." How difficult it must be to carry on waiting when the clinic to which one reaches out does not show them worthy of reaching back.

Contact as it is lived within the clinician-patient relation during the waiting period prior to weight loss surgery may be an invitation. It may be a way of genuine being with or seeing the 
Other. The seemingly ordinary chatter of the nurse or a conversation that is truly conversational may make the worries of the weight/wait fall away. These gestures may show the person waiting that she is seen as a person, as more than a body awaiting intervention. The listening silence between clinician and patient may invite a person into honest relation; invite her to be herself, to reveal herself as she is without judgment and shame. The hiding of one's true self, nodding one's head and carrying on, and 'saying whatever they want me to say' may be a response to shame or fear, both of which a person hoping to access bariatric surgery may feel. What are the possible consequences of the patient who does not show her self as she truly is within the clinical relation? She may gain access to the surgery she so desires; yet I wonder if she will receive the care she needs and deserves?

The trusting relation established through the attentive attitude of clinician to patient, the seeing of the Other, during the waiting period prior to weight loss surgery, may shift the dynamics of the relationship, opening it to new and more tactful possibilities. Whereas, contact that refuses to see or recognize the Other in their Otherness, the asking of questions without waiting for answers and the assumptions that reduce to the 'general case' may act as closures. They may shut off potential ethical ways of being with and seeing within clinical encounters that take place during the wait to have bariatric surgery.

\section{Acknowledgements}

I acknowledge the support, feedback and guidance of my supervisors Drs. John C. Spence and Kim Raine. I thank my phenomenological writing group, Erika Goble, Kathy Howery and Iris Yin, for their invaluable contribution and support. I acknowledge the financial support received from a Canadian Institutes of Health Research obesity-training grant. Above all I thank my participants for their extremely generous contributions.

\section{References}

Barber, K. (Ed.). (2004). Canadian Oxford Dictionary. Toronto, Canada: Oxford University Press.

Baron, R. J. (1985). An introduction to medical phenomenology: I can't hear you while I'm listening. Annals of Internal Medicine, 103, 606-611.

Brown, J., Sorrell, J. H., McClaren, J., \& Creswell, J. W. (2006). Waiting for a liver transplant. Qualitative Health Research, 16(1), 119-136.

Christou, N. V., \& Efthimiou, E. (2009). Bariatric surgery waiting times in Canada. Canadian Journal of Surgery, 52(3), 229-234.

Conversation. (n. d.). Online Etymology Dictionary. From http://www.etymonline.com/index.php?term $=$ conversation\&allowed in frame $=0$ 
Drew, P. (2008). Weight loss surgery patients' negotiations of medicine's institutional logic. Research in the Sociology of Health Care, 26, 65-92.

Drew, P. (2011). "But then I learned...": Weight loss surgery patients negotiate surgery discourse. Social Science \& Medicine, 73(8), 1230-1237. doi: http://dx.doi.org/10.1016/j.socscimed.2011.07.023

Levinas, E. (2006). Humanism of the Other. (N. Poller, Trans.). Chicago: University of Illinois Press.

Levinas, E. (1978). Existence \& Existents (E. Lingis, Trans). Pittsburgh, PE: Duquesne University Press.

Lingis, A. (2005). Contact. Janus Head, 8(2), 439-454.

Lingis, A. (2007). Contact: Tact and caress. Journal of Phenomenological Psychology, 38, 1-6.

Lupton, D. (2013). Fat. New York, NY: Routledge.

Meleo-Erwin, Z. C. (2011). 'A beautiful show of strength': Weight loss and the fat activist self. Health, 15(2), 188-205. doi: 10.1177/1363459310361601

Meleo-Erwin, Z. C. (2012). “I Just Couldn't Keep it in Control Anymore:” Weight Loss Surgery, Food Addiction, and Anti-Fat Stigma. In J. Netherland (Ed.), Critical Perspectives on Addiction (Advances in Medical Sociology, Volume 14; pp. 201-224), Emerald Group Publishing Limited.

Murray, S. (2009). 'Banded bodies': The somatechnics of gastric banding. In N. Sullivan \& S. Murray (Eds.) Somatechnics: Queering the technicalisation of bodies (pp. 155-168). Burlington, VT: Ashgate publishing.

Murray, S. (2008a). Marked as 'pathological.' 'fat' bodies as virtual confessors. In J. Wright, \& V. Harwood (Eds.), Biopolitics and the 'obesity epidemic.' governing bodies (pp. 78-93). New York: Routledge.

Murray, S. (2008b). The 'fat' female body. New York, NY: Palgrave Macmillan.

Neff, K. J., Olbers, T., leRoux, C. W. (2013). Bariatric surgery: The challenges with candidate selection, individualizing treatment and clinical outcomes. BioMed Central Medicine, 11, $8-25$.

Padwal, R. S., Chang, H. J., Klarenbach, S., Sharma, A. M., \& Majumdar, S. R. (2012a). Characteristics of the population eligible for and receiving publicly funded bariatric surgery in Canada. International Journal for Equity in Health, 11, 54-62. doi:10.1186/1475-9276-11-54 
Padwal, R. S., Majumdar, S. R., Klarenbach, S., Birch, D. W., Karmail, S., McCargar, L., et al. (2012b). Health status, quality of life, and satisfaction of patients awaiting multidisciplinary bariatric care. BMC Health Service Research, 12, 139-149. doi: 10.1186/1472-6963-12-139

Parsons, G. E., Godfrey, H., \& Jester, R. F. (2009). Living with severe osteoarthritis while awaiting hip and knew joint replacement surgery. Musculoskeletal Care, 7(2), 121-135. doi: $10.1002 . \mathrm{msc} .145$

Robbins, J. (Ed.) (2001). Is it righteous to be? Interviews with Emmanuel Levinas. Stanford, CA: Stanford University Press.

Scott-Dixon, K. (2008). Big girls don't cry: Fitness, fatness, and the production of feminist knowledge. Sociology of Sport Journal, 25, 22-47.

Sjöling, M., Ågren, Y., Olofsson, N., Hellzén, O., \& Asplund, K. (2005). Waiting for surgery; living a life on hold -- a continuous struggle against a faceless system. International Journal of Nursing Studies, 42(5), 539-547.

Taylor, A. (2013, May 10). An open letter from a 'fat chick' to Mike Jeffries, CEO of Abercrombie and Fitch [online news article]. The Huffington Post online. Retrieved from http://www.huffingtonpost.com/amy-taylor/open-letter-fat-chick-mike-jeffries-ceoabercombie-fitch b 3249798.html

Throsby, K. (2008). Happy re-birthday: Weight-loss surgery and the "new me." Body and Society, 14(1), 117-133. doi:10.1177/1357034X07087534

Van Manen, M. (1990). Researching lived experience. Albany: State University of New York Press.

Van Manen, M. (1999). The pathic nature of inquiry and nursing. In. I. Madjar \& J. Walton (Eds.). Nursing and the experiences of illness: Phenomenology in practice. London: Routledge, 17-35.

Van Manen, M. (2012). The call of pedagogy as the call of contact. Phenomenology \& Practice, $6(2), 8-34$.

World Health Organization. (2011). Obesity and overweight. Retrieved from http://www.who.int/mediacentre/factsheets/fs311/en/ (accessed September 2011).

${ }^{\mathrm{i}}$ I include here a brief description of the literature from which these statements are drawn. Critical scholars contribute significantly to understandings of fatness/obesity and related treatments and have exposed the complex and often problematic nature of living with, through and in 'obese' bodies and reducing through surgical means (Drew, 2008, 2011; Lupton, 2013; 
Meleo-Erwin, 2011, 2012; Murray, 2008a, 2008b, 2009; Throsby, 2008). They show how fatness is, for example, equated with moral failure, obesity with pathology and bariatric surgery as 'the easy way out' (Thorsby, 2008; Murray, 2009). These critical and discursive explorations show the re/productive capacities of language and the power of dominant knowledges and discourses to shape experiences and understandings of self, other and world (Lupton, 2013; Meleo-Erwin, 2011, 2012; Murray, 2008a, 2008b, 2009; Throsby, 2008). These understandings may shape the experiences of the people who pursue bariatric surgery, affecting how they think about their bodies, the procedure and the post-surgical future (among other things). It is within these discourses that individuals seeking bariatric surgical care may be positioned and, furthermore, where they may position themselves. 